\title{
Validation of a FFQ (Food Frequency Questionnaire) for Older People
}

\author{
José Eduardo Corrente ${ }^{1}$, Dirce Maria Lobo Marchioni ${ }^{2}$ and Regina Mara Fisberg ${ }^{2}$ \\ 1. Department of Biostatistics, State University of São Paulo (UNESP), Botucatu 18718-900, São Paulo, Brazil \\ 2. Department of Nutrition, University of São Paulo (USP), São Paulo 01246-904, Brazil
}

Received: January 31, 2013 / Accepted: April 19, 2013 / Published: August 30, 2013.

\begin{abstract}
Nutrition data for older adults is an area that has few studies mainly in Brazil. Due to the importance to know the behavior of this age group, the aim of this study was to develop and validate a frequency food questionnaire (FFQ) for older people in Brazil. It was considered a sample of 73 subjects from the city of Avaré, São Paulo, Brazil, and it was applied three 24-hour recalls and a FFQ developed for adults. Data from the three 24-hour recalls were transformed in nutrient intake as well as the data from FFQ. Statistical analysis was performed in order to get correlations between data from the mean of three 24-hour recalls and FFQ for some nutrients. It was found high correlations among them, concluding that the FFQ is valid to get nutrient intakes for older people.
\end{abstract}

Key words: Older people, food frequency questionnaire, correlations, nutrient intake.

\section{Introduction}

The age distribution of the world population has brought visible changes in recent decades due to the increase in life expectancy and the consequent increase in the older people which represents new challenges in the field of nutritional research. In Brazil, like the other Latin American countries, it is undergoing a rapid and intense process of aging making it important to know the behavior of this group. The nutritional situation of the Brazilian older population points out the need to seek, know and understand all the peculiarities that affect food intake taking into account regional characteristics in which they are inserted [1].

A common purpose of dietary assessment is to evaluate the dietary intake of a group or population in relation to some standard, with respect to both nutrient adequacy and the prevention of chronic disease [2]. In this way, FFQs (Food Frequency Questionnaires) are a cost-effective, widely used method of dietary

Corresponding author: José Eduardo Corrente, Ph.D., associate professor, research field: epidemiology of the third age. E-mail: jecorren@ibb.unesp.br. assessment in epidemiologic studies and are a virtual necessity within the largest studies, like prospective cohort studies, when the goal is to elicit a comprehensive estimate of subjects' average diets. At a minimum, FFQs determine how often a subject consumes foods that fall within a defined category [3].

A FFQ was developed for adults (men, women and both genders) from information derived from the study "Food Surveys in São Paulo" integrating the project "Survey of Health Status in São Paulo-Health Survey population-based", based on dietary information obtained through the 24HR (24-hour recall) [4]. The initial version of the FFQ was composed by 67 items and the final version of the FFQ presented a list of 60 foods for women, 59 for men and 60 for both genders.

Since that FFQ was developed and validated for adults, the aim of this study was to validate this instrument for the older population (60 years-old and over).

\section{Methods}

Cross-sectional study of dietary intake, carried out 
in the city of Avaré, São Paulo, Brazil. The sample consisted of 73 individuals of both sexes (representing $20 \%$ of a sample of 365 older people obtained to assess quality of life, from an unknown prevalence of $50 \%$, margin of error of $5 \%$, confidence coefficient 95\%, enrolled in the Family Health Program and Basic Health Units of the municipality). There were no refusals to participate but four individuals were excluded from the final sample due to cognitive difficulties in answering the questions of the instruments.

Data were collected from January to March, 2009. All interviews were conducted at home by a single trained interviewer. It used an instrument consisting of three parts: identification questionnaire, a R24h (24-hour recall) and the cited questionnaire quantitative food frequency developed for adults (FFQ).

The following data were collected: sex, age, ethnicity, education, consumption of supplements, medications and physical activity.

The sequence of application of the instruments was: on the first day, applied the identification questionnaire, the FFQ and a R24h1 (24-hour recall) in a weekday; a second R24h necessary on Monday (R24h2) to get the intake from the weekend, and a third R24h in a weekday different form the first one (R24h3).

The FFQ was composed of 67 items and four choices of food serving sizes. For its fulfillment, it was asked to the participant to remember the frequency of consumption (from 0 to 10 times per day, week, month or year) of each food item in the proposed questionnaire as well as the portion size consumed.

For the application of the R24h, standard form was used and was followed by multiple pass method [5, 6]. All R24hs were reviewed critically by trained nutritionists. The portion sizes were transform into weight [7] using a table developed from a population study [4]. For quantification of nutrients NutWin
(Nutrition Support Program NutWin, Version 1.5, 2002) software was used. A photographic record of fixtures and parts was used in order to help older people to complete the FFQ [8].

The statistical analysis was done initially by a description of the sample characteristics by descriptive measures (percentages for qualitative variables and mean and standard deviation for quantitative variables). Nutrient intakes were described by calculating averages and standard deviations. The adjustment of the distribution of consumption using within-person variability for the R24h was made by the method proposed by the Iowa State University (ISU), using PC-SIDE (Software for Intake Distribution Estimation, Version 1.0, 2003) software, provided by the Department of Statistics, Iowa State University, Ames, IA, USA.

The Pearson correlation coefficient was used to verify the linear correlations in consumption (FFQ and the 24-hour recalls). The consumption data (FFQ and 24-hour recalls) were also divided into quartiles of intake and obtained the agreement between the two instruments using the kappa coefficient. All analyzes were performed using SAS, V.9.2.

In accordance with national and international guidelines for research with human subjects Council for International Organization of Medical Sciences (CIMS) and Resolution No. 196/96 of the National Health Council (BRAZIL, 1996), this project was submitted to the Ethics Committee of the Faculty of Medicine of Botucatu, SP.

3. Results and DiscussionThe mean age of the 73 older people that participated of this study was 71.51 years $(\mathrm{SD}=6.48$ years), $80 \%$ had elementary school and the mean water consumption was $1130.48 \mathrm{~mL}$ $(\mathrm{SD}=588.99 \mathrm{~mL})$. Table 1 shows the description of the other sample characteristics.

In order to validate the FFQ for the older population, it was analyzed the consumption of calcium,

Table 1 Frequencies and percentages of the older people 
in the sample, Avaré, 2009.

\begin{tabular}{|c|c|c|}
\hline Variable & $\mathrm{N}$ & $\%$ \\
\hline \multicolumn{3}{|l|}{ Sex } \\
\hline Male & 32 & 43.84 \\
\hline Female & 41 & 56.16 \\
\hline \multicolumn{3}{|l|}{ Ethnicity } \\
\hline White & 69 & 94.52 \\
\hline Black & 3 & 4.11 \\
\hline Yellow & 1 & 1.37 \\
\hline \multicolumn{3}{|l|}{ Nutricional Status } \\
\hline Malnutrition & 9 & 12.64 \\
\hline Eutrophic & 36 & 50.70 \\
\hline Obese & 26 & 36.62 \\
\hline \multicolumn{3}{|l|}{ Dentition (use of denture) } \\
\hline Yes & 14 & 19.18 \\
\hline No & 59 & 80.82 \\
\hline \multicolumn{3}{|l|}{ Use of supplement } \\
\hline Yes & 13 & 17.81 \\
\hline No & 59 & 80.82 \\
\hline \multicolumn{3}{|l|}{ Medication } \\
\hline Pressure & 34 & 58.62 \\
\hline Others & 24 & 41.38 \\
\hline \multicolumn{3}{|l|}{ Bowel function } \\
\hline Normal & 55 & 75.34 \\
\hline Constipated or diarrhea & 18 & 24.66 \\
\hline \multicolumn{3}{|l|}{ Tobaco } \\
\hline Yes & 8 & 10.96 \\
\hline No & 65 & 89.04 \\
\hline \multicolumn{3}{|l|}{ Physical activity } \\
\hline Yes & 26 & 35.62 \\
\hline No & 47 & 64.38 \\
\hline
\end{tabular}

carbohydrates, copper, cholesterol, energy, iron, dietary fiber, folate, phosphorus, lipids, magnesium, manganese, niacin, potassium, protein, riboflavin, sodium, thiamin, vitamin A (IU), vitamin A (RE), vitamin $B 12$, vitamin $B$, vitamin $C$, vitamin $E$ and zinc.

Table 2 shows the descriptive statistics of the raw and deattenuated consumption of nutrients considered from three 24-hour recalls.

Due to the high variability of some nutrients, intakes of energy, carbohydrates, protein, folate, calcium, magnesium, iron, zinc, copper, potassium and manganese were considered to validate the FFQ.

Initially, the consumed quantities of the considered food in FFQ using the portion size were calculated as follows:

$$
\begin{aligned}
& \text {-P25—-small portion } \\
& \text {-P50—-the middle portion } \\
& \text {-P75-large portion } \\
& \text {-P95- extra-large portion }
\end{aligned}
$$

from a population study data carried out by the Faculty of Public Health, University of São Paulo for the adult population [4]. Then, through the reported amount for the older people, data were transformed

Table 2 Mean and standard deviation of the obtained consumption form three 24-hour recalls (raw and deattenuated values), Avaré, 2009.

\begin{tabular}{lrrrr}
\hline \multirow{2}{*}{ Nutrients } & \multicolumn{2}{c}{ Raw } & \multicolumn{2}{c}{ Deattenuated } \\
\cline { 2 - 3 } Vitamin E (mg) & \multicolumn{1}{c}{ Mean } & \multicolumn{1}{c}{ SD } & Mean & \multicolumn{1}{c}{ SD } \\
Zinc (mg) & 9.18 & 4.09 & 6.18 & 3.09 \\
Vitamin C (mg) & 6.99 & 271.63 & 149.12 & 192.79 \\
Vitamin B12 (mg) & 149.12 & 3.54 & 2.81 & 2.12 \\
Vitamin A (RE) & 2.81 & 760.72 & 534.26 & 412.40 \\
Calcium (mg) & 534.26 & 394.25 & 583.57 & 339.99 \\
Energy (kcal) & 583.57 & 649.97 & 1575.68 & 570.33 \\
Carbohydrates (g) & 1575.68 & 101.29 & 210.74 & 87.51 \\
Protein (g) & 210.74 & 31.77 & 61.27 & 26.96 \\
Lipids (g) & 61.27 & 24.72 & 54.74 & 20.18 \\
Magnesium (mg) & 54.74 & 100.82 & 185.62 & 81.75 \\
Manganese (mg) & 185.62 & 1.06 & 1.52 & 0.93 \\
Folate (mg) & 1.52 & 102.27 & 147.83 & 88.60 \\
Phosphorus (mg) & 147.83 & 411.42 & 835.27 & 369.95 \\
Iron (mg) & 835.27 & 5.97 & 10.55 & 5.02 \\
Copper (mg) & 10.55 & 0.50 & 0.86 & 0.42 \\
Potassium (mg) & 0.86 & 1118.42 & 1928.40 & 881.11 \\
\hline
\end{tabular}


Table 3 Correlations between the mean of the intake obtained from three 24-hour recalls (raw and deattenuated) and the intake form FFQ for 73 and 69 olders, Avaré, 2009.

\begin{tabular}{|c|c|c|c|c|}
\hline & $\begin{array}{l}\text { FFQ } \times \text { Raw mean } \\
(N=73)\end{array}$ & $\begin{array}{l}\text { FFQ } \times \text { Deattenuated mean } \\
(N=73)\end{array}$ & $\begin{array}{l}\text { FFQ } \times \text { Raw mean } \\
(N=69)\end{array}$ & $\begin{array}{l}\text { FFQ } \times \text { Deattenuated mean } \\
(N=69)\end{array}$ \\
\hline Energy (kcal) & 0.6151 & 0.6151 & 0.7181 & 0.7181 \\
\hline Carbohydrates (g) & 0.6614 & 0.6613 & 0.7836 & 0.7836 \\
\hline Protein (g) & 0.5786 & 0.5787 & 0.6226 & 0.6226 \\
\hline Folate (mg) & 0.7524 & 0.7524 & 0.8354 & 0.8354 \\
\hline Calcium (mg) & 0.5177 & 0.5177 & 0.5603 & 0.5602 \\
\hline Phosphorus (mg) & 0.6113 & 0.6112 & 0.6724 & 0.6724 \\
\hline Magnesium (mg) & 0.6667 & 0.6667 & 0.7728 & 0.7728 \\
\hline Iron (mg) & 0.6534 & 0.6534 & 0.7574 & 0.7573 \\
\hline Zinc (mg) & 0.5698 & 0.6797 & 0.5928 & 0.5928 \\
\hline Copper (mg) & 0.7212 & 0.7217 & 0.8274 & 0.8280 \\
\hline Potassium (mg) & 0.6603 & 0.6603 & 0.7334 & 0.7334 \\
\hline Manganese (mg) & 0.6413 & 0.6412 & 0.7074 & 0.7075 \\
\hline
\end{tabular}

Table 4 Kappa coefficient calculated from the quantiles of nutrient intake obtained by the mean of three 24-hour recalls and then FFQ for older people, Avaré, 2009.

\begin{tabular}{lll}
\hline Nutrient & Kappa & Weighted Kappa \\
\hline Energy (kcal) & - & - \\
Carbohydrates (g) & 0.2671 & 0.4658 \\
Protein (g) & - & - \\
Folate (mg) & - & - \\
Calcium (mg) & 0.1779 & 0.3667 \\
Phosphorus (mg) & 0.3058 & 0.4985 \\
Magnesium (mg) & 0.2327 & 0.3677 \\
Iron (mg) & 0.3056 & 0.4252 \\
Zinc (mg) & 0.3675 & 0.4622 \\
Copper (mg) & 0.2506 & 0.4767 \\
Potassium (mg) & 0.2327 & 0.3677 \\
Manganese (mg) & - & - \\
\hline
\end{tabular}

into nutrient intake by making a proportionality to $100 \mathrm{~g}$ of each food consumption table which was supplied by the same study carried out for adults. The calculations were performed using the SAS software for Windows, v.9.2.

Table 3 shows the correlations between the mean value of three 24-hour recalls of the considered nutrient intake values (gross and deattenuated) and the intake obtained by FFQ. Due to low levels of energy and consequently of the nutrients considered, some of the elderly were removed from the sample. This happened because the values may have been reported erroneously, making consumption far below or far above that expected for a normal individual. Thus, the correlations between the average of the three 24-hours recalls and the FFQ were recalculated to 69 people.

According to Table 3, values of correlations were quite acceptable between the consumption measured by the proposed FFQ and the average of three recalls 24 hours (raw and deattenuated), since the literature, in general, these correlations are smaller [9-11]. Note that the correlations were almost equal in both cases (raw and deattenuated), since no significant difference was obtained among intakes from three days of 24-hour recalls. This means that the reduction in a within-person variability was very small, showing that the consumption among older people are quite monotone.

Using again the average of three 24-hour recalls and consumption assessed by FFQ proposed, quartiles of intake between the two methods were obtained and evaluated the concordance between them using the Kappa coefficient. The results are shown in Table 4.

According to Table 4 and considering the value of weighted kappa, quartiles of intake between the two instruments were reasonable.

\section{Conclusions}

FFQ validation studies in Brazil are still scarce in the literature especially regarding to older population, making it difficult establish some comparisons with other studies. 
Even though and according to the results obtained in this study, it can be concluded that the proposed FFQ is valid to assess consumption of the older people. Nevertheless, it is noted that, for this age group, there is a great variability in the diet, which makes the instrument long and somewhat underestimate the consumption of macro and micro nutrients. This is somewhat expected, since in old age, several problems can occur when doing an interview in order to assess consumption. Some of these problems are expected like cognitive deficit, impaired memory and others that affect the reliability of responses. Added to this, the socio-demographic characteristics, comorbidities, teething problems and subjects were with low income. Nonetheless, with this study, it was found a good correlation between recalls 24 hours and the results obtained by FFQ consumption. It is strongly recommended, therefore, that the instrument is more widely used by other health services in order to be refined and reproducible for this age group and as an easy and reliable way to get assessment of usual intake for older adults.

\section{Acknowledgments}

The authors would like to thank to CNPq (Processes number 402533/2007-0 and 301197/2011-3) for the financial support to carry out this research and to Maira Barreto Malta for data collection.

\section{References}

[1] M.T.F.S. Campos, J.B.R. Monteiro, A.P.R.C. Ornelas, Factors that affect the aged people food intake, Brazilian Journal of Nutrition 13 (3) (2000) 157-165.

[2] K. Dood, P.M. Guenther, L.S. Freeman, A.F. Subar, V. Kipinis, D. Midthune, et al., Statistical methods for estimating usual intake of nutrients and foods: A review of theory, J. Am. Diet Assoc. 105 (2006) 1640-1650.

[3] L.B. Signorello, H.M. Munro, M.S. Buchowski, D.G. Schlundt, S.S. Cohen, M.K. Hargreaves, et al., Estimating nutrient intake from a food frequency questionnaire: Incorporating the elements of race and geographic region, Am. J. Epidemiol 170 (2009) 104-111.

[4] R.M. Fisberg, A.C. Colucci, J.M. Morimoto, D.M. Marchioni, Food frequency questionnaire for adults from a population-based study, Rev. Saude Publica. 42 (3) (2008) 550-554.

[5] R.K. Johnson, P. Driscoll, M.I. Goran, Comparison of multiple-pass 24-hour recall estimates of energy intake with total energy expenditure determined by the doubly labeled water method in young children, J. Am. Diet Assoc. 96 (11) (1996) 1140-1144.

[6] A.F. Subar, F.E. Thompson, N. Potischman, B.H. Forsyth, R. Budday, D. Richards, et al., Formative research of a quick list for an automated self-administered 24-hour dietary recall, J. Am. Diet Assoc. 107 (6) (2007) 1002-1007.

[7] A.B.V. Pinheiro, E.M.A Lacerda, E.H. Benzecry, M.C.S. Gomes, V.M. Costa, Table for Assessment of Food Consumption Measurements in Homemade, 5th ed., Atheneu, São Paulo, 2004. (in Portuguese)

[8] C.B. Zaboto, R.P.T. Viana, M.F. Gil, Photographic Record to Dietetic Inquiries-Appliances and Portions, Federal University of Goiás Ed, Goiania, Brazil, 1996, p. 74. (in Portuguese)

[9] J.A. Teixeira, Validity, reproducibility and calibration of a Brazilian quantitative food frequency questionnaire used in the study Natural History of HPV Infection in Men: The HIM Study, M.Sc. Thesis, Nutrition Department, Public Health Faculty, University of São Paulo, Brazil, 2009. (in Portuguese)

[10] W. Smith, P. Mitchel, E.M. Reay, K. Webb, P.W.J. Harvey, Validity and reproducibility of a self-administered food frequency questionnaire in older people, Australian and New Zealand Journal of Public Health 22 (4) (1998) 456-463.

[11] M. Haftenberger, T. Heuer, C. Heidemann, F. Kube, C. Krems, G.B.M. Mensink, Relative validation of a food frequency questionnaire for national health and nutrition monitoring, Nutrition Journal 9 (36) (2010) available online at: http://www.nutritionj.com/content/9/1/36 DOI:10.1186/1475-2891-9-36. 